\title{
Numerical estimation of temperature field in a laser welded butt joint made of dissimilar materials
}

\author{
Zbigniew Saternus ${ }^{1}{ }^{*}$ Wiesława Piekarska ${ }^{1}$, Marcin Kubiak ${ }^{1}$, Tomasz Domański ${ }^{1}$, \\ Dorota Goszczyńska-Króliszewska ${ }^{1}$ \\ ${ }^{1}$ Czestochowa University of Technology, Faculty of Mechanical Engineering and Computer Science, \\ Czestochowa, Poland
}

\begin{abstract}
The paper concerns numerical analysis of thermal phenomena occurring in the butt welding of two different materials by a laser beam welding. The temperature distribution for the welded butt-joint is obtained on the basis of numerical simulations performed in the ABAQUS program. Numerical analysis takes into account the thermophysical properties of welded plate made of two different materials. Temperature distribution in analysed joints is obtained on the basis of numerical simulation in Abaqus/Standard solver, which allowed the determination of the geometry of laser welded butt-joint.
\end{abstract}

Keywords: Numerical modelling, laser welding, dissimilar materials, temperature field, Abaqus

\section{Introduction}

The main objective of optimization of welding technology is to reduce the cost of production and the mass of joined elements while maintaining optimum durability $[1,2]$. One of the new trends in the welding industry is performing welded joints with dissimilar materials [2-5]. These types of welded structures are commonly used today in aviation, construction of steam power plants, chemical installations etc. Depending on the combination of materials used, for example: austenitic stainless steel - non-austenitic steel or austenitic stainless steel - copper/copper alloy, the required strength, anti-corrosion and heat properties must be obtained from performed joints [5]. Another aspect which supports the use of dissimilar joints is the economic factor.

Welding of dissimilar materials is quite complicated because of the large differences in material behavior of joined materials [2-4]. The most important parameters of the joined materials are: the melting temperature, thermal conductivity and thermal expansion coefficient. Issues in joined materials occur when more than one of these conditions are present at the same time [5].

Most often arc welding or laser beam welding are used in in this type of joints. Each of these technologies involves specific conditions of heat distribution in the analyzed joints

\footnotetext{
*Corresponding author: saternus@imipkm.pcz.pl

Reviewers: Alžbeta Sapietová, Ján Vavro Jr.
} 
$[3,6,7]$. The quantity of heat impact into the welded material has a significant effect on the microstructure change and joint deformation $[7,8]$.

Performing experiments of dissimilar materials joining is quite expensive as it requires many experimental tests to determine the proper parameters of the welding process. Sasaki and Ikeno in the study [9] conducted experiments on laser welding of butt joints made of dissimilar materials - austenitic steel and brass. They experimentally analyzed the influence of parameters such as: laser beam focus, power change and welding speed of heat source on the quality of the resulting joints. Figure 1 shows exemplary welds for different positioning of welding heat source.

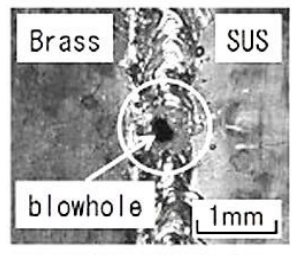

(a) SUS side $0.4 \mathrm{~mm}$

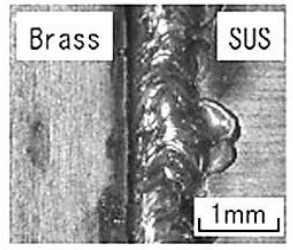

(b) SUS side $0.2 \mathrm{~mm}$

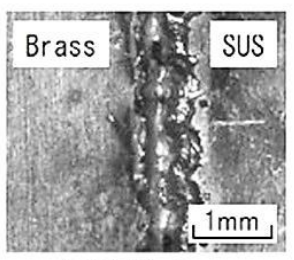

(c) Butt face

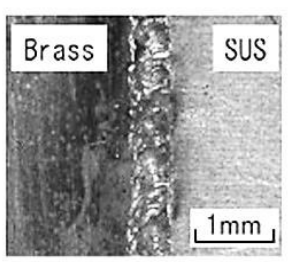

(d) Brass side $0.2 \mathrm{~mm}$

Fig. 1. View of welded beads for laser welded butt joint [9]

Due to the cost of experiments, numerical modeling becomes a useful tool for analyzing the relevant technological parameters of the process $[10,11]$. Numerical modeling can greatly reduce costs of experimental research at the initial stage of construction design [6, $9,12]$. An important case of study in numerical research is a reliable representation of the real process and the appropriate adaption of mathematical and numerical models of the analyzed phenomena.

Numerical analysis of laser welded butt joint made of two dissimilar materials: austenitic steels X5CrNi18-10 and brass CuSn10 is performed in this study. The presented numerical analysis is based on experimental studies from literature [9]. Numerical simulations are performed in the Abaqus/FEA computational software. A three dimensional discrete model of the discussed system is developed with temperature dependent thermophysical properties of analyzed materials taken into account. In order to provide a moveable welding source in the model the implementation of additional numerical subroutine DFLUX is necessary. Temperature distribution and size of the melted zone in the laser welded butt joint are estimated on the basis of performed numerical simulations.

\section{Modelling of thermal phenomena in Abaqus}

Numerical analysis of thermal phenomena occurring in the welding process of welded butt joint made of disimilar materials is difficult to carry out. It requires taking into account the specific conditions of the laser beam welding process and taking into account the different thermophysical properties of the joined materials (Fig. 2). The numerical model of the movable welding source requires implementation of additional subroutine DFLUX in Abaqus software. 


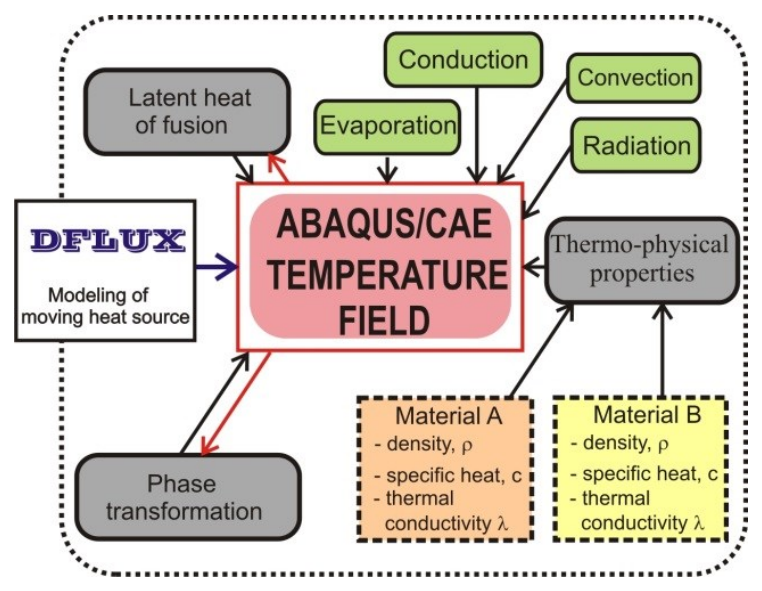

Fig. 2. Scheme of coupled thermal phenomena

The numerical analysis of heat transfer in the Abaqus software is based on the energy conservation equation and Fourier's law, expressed as follows [6, 13]:

$$
\int_{V} \rho \frac{\partial U}{\partial t} \delta T d V+\int_{V} \frac{\partial \delta T}{\partial x_{\alpha}} \cdot\left(\lambda \frac{\partial T}{\partial x_{\alpha}}\right) d V=\int_{V} \delta T q_{V} d V+\int_{S} \delta T q_{S} d S
$$

where $\lambda$ is a thermal conductivity $\left[\mathrm{W} / \mathrm{m}{ }^{\circ} \mathrm{C}\right], U=U(T)$ is a internal energy $[\mathrm{J} / \mathrm{kg}], q_{v}$ is a laser beam heat source $\left[\mathrm{W} / \mathrm{m}^{3}\right], T=T\left(x_{\omega}, t\right)$ is a temperature $\left[{ }^{\circ} \mathrm{C}\right], q_{s}$ is a boundary heat flux $\left[\mathrm{W} / \mathrm{m}^{2}\right], \delta T$ is a variational function, $\rho$ is a density $\left[\mathrm{kg} / \mathrm{m}^{3}\right], T=T\left(x_{\alpha}, t\right)$ is temperature $\left[{ }^{\circ} \mathrm{C}\right]$.

Temperature field is expressed in the criterion of weighted residuals method. Simulations are carried out in Lagrange's coordinates, where coordinates of the center of heat source is determined at each time step, depending on the welding speed [6]. Equation (1) is completed by the initial condition $t=0: T=T_{0}$ and boundary conditions of Dirichlet and Neumann and Newton type, which takes into account the heat loss to convection, radiation and evaporation [14]:

$$
\left.T\right|_{\Gamma}=\widetilde{T} \quad q_{S y m}=-\lambda \frac{\partial T}{\partial n}=0 \quad q_{S}=-\lambda \frac{\partial T}{\partial n}=\alpha_{k}\left(\left.T\right|_{\Gamma}-T_{0}\right)+\varepsilon \sigma\left(\left.T\right|_{\Gamma}{ }^{4}-T_{0}^{4}\right)
$$

where $\alpha_{k}$ is convective coefficient, $\varepsilon$ is radiation $(\varepsilon=0.5), \sigma$ is Stefan-Boltzman constant and $q(r, 0)$ is the heat flux towards the top surface of welded workpiece $(z=0)$ in the source activity zone of radius $r, T_{0}=20^{\circ} \mathrm{C}$ is an ambient temperature.

Most widely used mathematical model of heat source power having Gaussian type distribution is used in numerical model [15]. The presented model assumes a linear decrease of energy density along material penetration depth (Fig. 3), expressed as follows:

$$
q_{v}(r, z)=\frac{Q}{\pi r_{o}^{2} s} \exp \left[\left(1-\frac{r^{2}}{r_{o}^{2}}\right)\right]\left(1-\frac{z}{s}\right)
$$

where $Q$ is a laser beam power [W], $r_{0}$ is a beam radius [m], $r=\sqrt{x^{2}+y^{2}}$ is actual radius $[\mathrm{m}], s$ is penetration depth $[\mathrm{m}], z$ is actual penetration $[\mathrm{m}]$. 


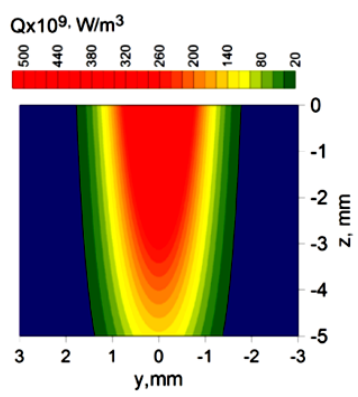

Fig. 3. Gaussian heat source power distribution along material penetration depth

The modeling of the moveable welding heat source in the Abaqus is performed through the additional DFLUX subroutine, written in the Fortran programming language.

\section{Numerical model}

The joint is made of two dissimilar materials: austenitic stainless steel X5CrNi18-10 and brass CuSn10. The dimensions of joined sheets are taken from the experimental study in literature [9], set as: $50 \times 25 \times 1.5 \mathrm{~mm}$. The scheme of the analyzed system is presented in Figure 4.

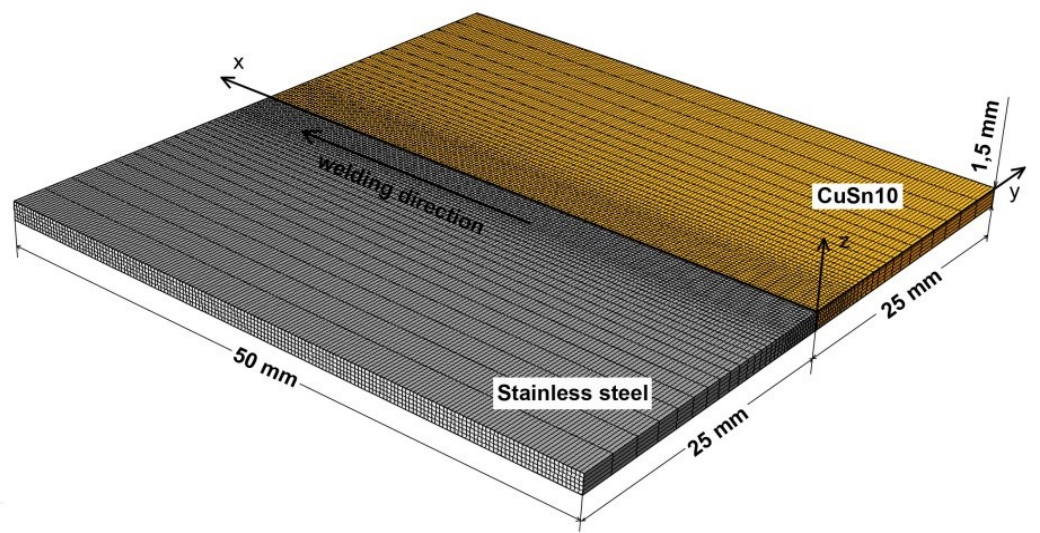

Fig. 4. Scheme of considered system

Perfect contact at the interface between joined parts is assumed in the developed numerical model of butt joints $[6,16]$. The finite element mesh is used to provide good quality results with not long duration of the time simulation. The size of finite element is assumed to be quite small in welding source activity zone, increasing linearly with the distance from the welding line. The total number of elements used in the numerical model is 30500 . The thermal analysis use rectangular finite element mesh, whit DC3D8 type of elements [13]. The calculations are carried out for three cases depending on the positioning center of the welding source (Fig. 5). 


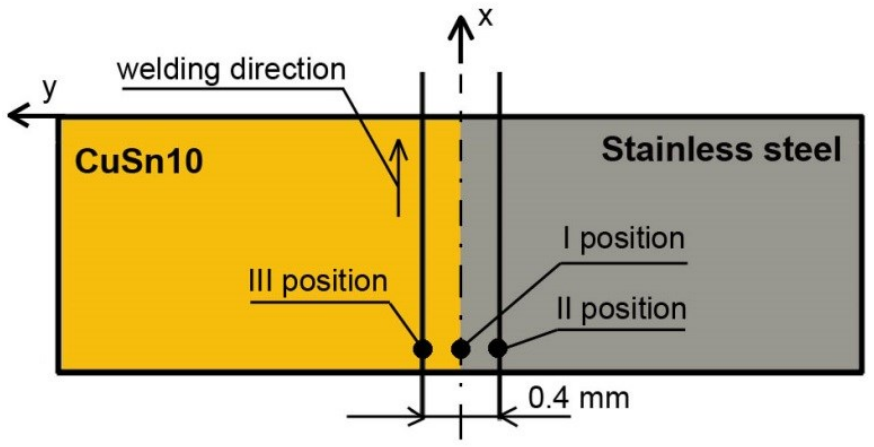

Fig. 5. Coordinates of the position of welding heat source central axis

Material model used in the analysis takes into account thermophysical properties of the welded materials changing with temperature. Figure 6 shows the assumed properties of austenitic steels, while in Figure 7 used in calculation properties of brass. Assumed in the analysis convective coefficient is set to: $\alpha_{k}=100 \mathrm{~W} / \mathrm{m}^{2}{ }^{\circ} \mathrm{C}$.

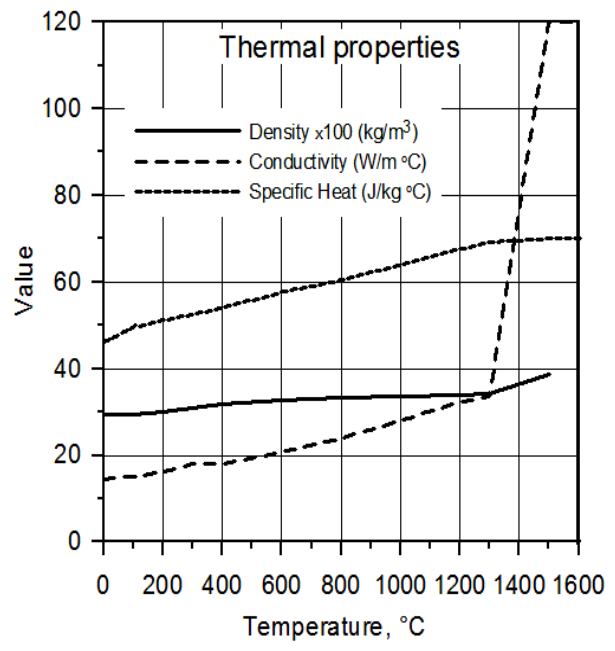

Fig. 6. Thermophysical properties of X5CrNi18-10 stainless steel

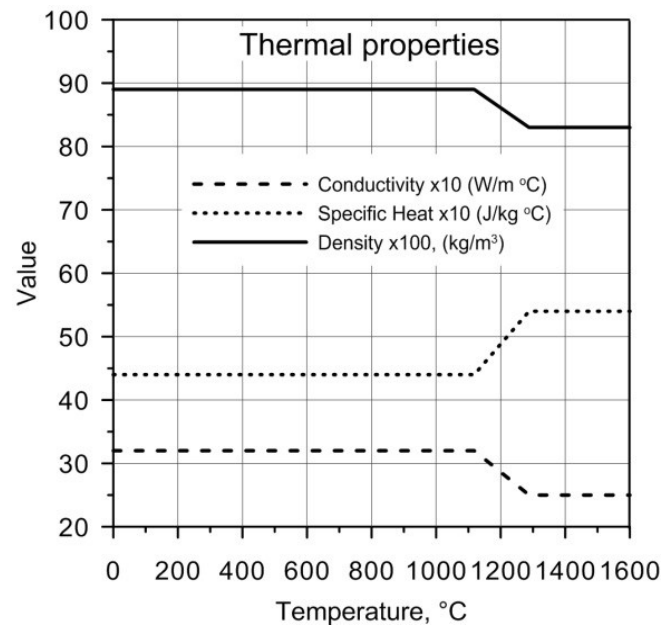

Fig. 7. Thermophysical properties of brass CuSn10

Solidus and liqidus temperatures for welded materials are:

- for austenitic stainless steel $-T_{S}=1400^{\circ} \mathrm{C}$ and $T_{L}=1455^{\circ} \mathrm{C}$, whereas latent heat of fusion $H_{L}=260 \times 10^{3} \mathrm{~J} / \mathrm{kg}$.

- for brass $-T_{S}=1118^{\circ} \mathrm{C}$ and $T_{L}=1280^{\circ} \mathrm{C}$, whereas latent heat of fusion $H_{L}=220 \times 10^{3} \mathrm{~J} / \mathrm{kg}$.

\section{Results and discussion}

The following numerical parameters of the heating source are assumed for numerical calculations of laser welding: beam power $Q=750 \mathrm{~W}$, welding beam diameter $r_{o}=0.4$ $\mathrm{mm}$, penetration depth $s=3.5 \mathrm{~mm}$ and welding speed $v=300 \mathrm{~mm} / \mathrm{min}$. The welding heat source parameters are taken from the literature [9]. Numerical calculations are performed in Abaqus/Standard solver. 
Temperature field and shape of melted zone are estimated in laser butt welded joints on the basis of performed numerical simulations. Figure 8 shows the temperature field in the joint for the positioning of welding source in the contact line of the joined sheets. The isoline $T_{L}$ is determined at the boundary of melted zone for each material.

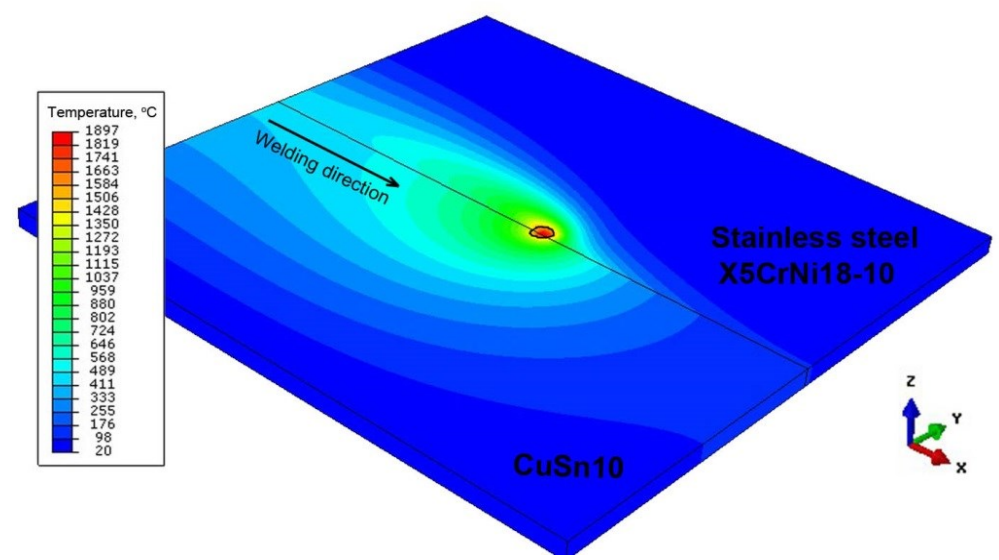

Fig. 8. Numerically estimated temperature field in laser welded butt joint

Figure 9 shows the temperature distribution in the cross section of welded joints. Presented figures indicated boundaries of melted zone for each analyzed material.

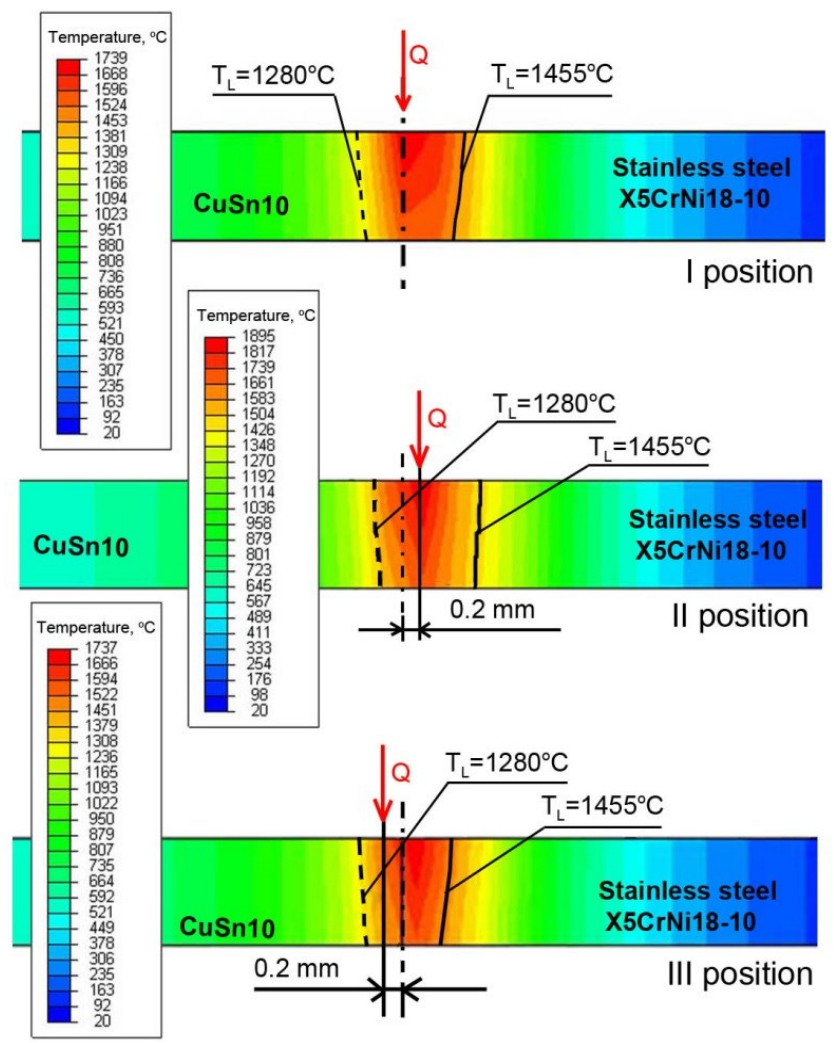

Fig. 9. Temperature field in the cross section of the joint for different positions of the heat source 
From the analysis of obtained simulation results it can be seen that for the III case of heat source $0.2 \mathrm{~mm}$ positioning on the brass side the narrowest zone melting is achieved. This result is also confirmed by experimental research [9].

\section{Conclusions}

It is difficult to obtain good quality welded joints of dissimilar materials because of the different thermophysical properties of joined materials. For significant differences between materials it is even more difficult to perform a good welded joint, which could have a high capacity to cracking. Numerical modeling of the welding process of dissimilar materials is a useful tool for engineers to determine a proper process parameters. Numerical prediction of thermal phenomena in welded elements, mainly temperature distribution, is a significant help in the initial stage of construction design. This can also significantly reduce the cost of conducting experimental research. The Abaqus software is a universal tool for analyzing laser beam welding process.

From the analysis of laser beam welding process of austenitic stainless steel to the brass it can be seen that the position of center of the heat source has a significant influence on the melted zone. The results of numerical simulations confirm the results of experimental work carried out by the authors of [9].

\section{References}

1. K. Ciechacki, T. Szykowny, Ocena jakości spawania różnoimiennych stali odpornych na korozje. Inż. Ap. Chem. 49 (5), 28-30 (2010)

2. Y. Li, Sh. Hu, J. Shen, L. Liu, Microstructures and mechanical properties of H62 brass-316L stainless steel in overlap welded joints by continuous-wave laser. Int J Adv Manuf. Technol. 79, 627-634 (2015)

3. N. Arivazhagan, S. Singh, S. Prakash, G. M. Reddy, Investigation on AISI 304 austenitic stainless steel to AISI 4140 low alloy steel dissimilar joints by gas tungsten arc, electron beam and friction welding. Materials \& Design 32, 3036-3050 (2011)

4. Ch. Shuhai, H. Jihua, X. Jun, Z. Xingke, L. Sanbao, Influence of processing parameters on the characteristics of stainlesssteel/copper laser welding. J Mater Process Tech. 222, 43-51 (2015)

5. http://www.wisconsinwireworks.com/dissimilar_metals.html

6. M. Kubiak, W. Piekarska, S. Stano, Z. Saternus, Numerical Modelling Of Thermal And Structural Phenomena In Yb:Yag Laser Butt-Welded Steel Elements. Arch Metall Mater. 60 (2), 821-828 (2015)

7. M. Kubiak, W. Piekarska, Z. Saternus, T. Domański, Numerical prediction of fusion zone and heat affected zone in hybrid Yb:YAG laser plus GMAW welding process with experimental verification. Procedia Eng. 136, 88-94 (2016)

8. T. Domański, W. Piekarska, M. Kubiak, Z. Saternus, Determination of the final microstructure during processing carbon steel hardening. Procedia Eng. 136, 77-81 (2016)

9. M. Sasaki, J. Ikeno, Laser Butt Welding of Brass and Stainless Steel. J Adv Mech Des Syst. 5 (4), 347-357 (2011)

10. V. Dekýš, A. Sapietová, O. Števka, Understanding of the dynamical properties of machines based on the interpretation of spectral measurements and FRF. Experimental stress analysis, Applied Mechanics and Materials 486, 106-112 (2014) 
11. T. Domanski, A. Sapietova, M. Saga, Application Of Abaqus Software For The Modeling Of Surface Progressive Hardening. Procedia Eng. 177, 64-69 (2017)

12. R. Koňár, M. Patek, Numerical Simulation Of Dissimilar Weld Joint In Sysweld Simulation Software. Tehnicki vjesnik 1, 137-142 (2017)

13. SIMULIA, Abaqus FEA theory manual. Version 6.7, Dassault System (2007)

14. L. Sowa, A. Bokota, Numerical simulation of the molten steel flow in the tundish of CSC machine. Arch Metall Mater. 57 (4), 1163-1169 (2012)

15. S.A. Tsirkas, P. Papanikos, Th. Kermanidis, Numerical simulation of the laser welding process in butt-joint specimens. J Mater Process Tech. 134, 59-69 (2003)

16. T. Skrzypczak, A finite element multi-mesh approach for heat transport between disconnected regions. Procedia Engineering 177, 204-209 (2017) 